\title{
Risk Factors for Hypospadias: A Case Control Study
}

\author{
Nahla A Nazmy*, Amal K Behery*
}

\begin{abstract}
Despite being one of the most common congenital defects in boys, the etiology of hypospadias remains largely unknown. In this study we evaluated a spectrum of potential risk factors for hypospadias in which we focused on both paternal and maternal factors and chromosomal aberrations. Cases were selected from the Genetic Clinic, Medical Research Institute, University of Alexandria. A total of 176 cases with hypospadias were included in this study, and a matching control group of normal 300 boys for the association study. All cases were subjected to detailed family, pregnancy, genetic histories, clinical examination, and pedigree study. Chromosome analysis was performed using peripheral blood lymphocyte cultures by trypsin G-banding technique. Hormonal assays, abdominal and pelvic ultrasound were carried out according to case presentation. Both parents of cases and the control group completed written questionnaires. Abnormal karyotyes were detected in 23 cases (13.07\%) associated with other anomalies, sex chromosome abnormalities were present in $69.56 \%$ and autosomal aberrations in $30.43 \%$. Patients with chromosomal abnormalities were excluded from the association study. Logistic regression analysis was used to assess the independent contribution of different factors to the risk of hypospadias. Our data did not support an association with increased parental age. The most profound result was the increased risk of hypospadias for boys with positive family history ( $n=23$; OR=26.36; 95\% Cl: $5.90-164.23$ ). Strong indications for an increased risk of hypospadias were also found with low birth weight $(n=45$; $\mathrm{OR}=13.47 ; 95 \% \mathrm{Cl}=6.09-30.70)$, preterm birth $(\mathrm{n}=6 ; \mathrm{OR}=12.20 ; 95 \% \mathrm{Cl}=1.45-271.47)$, twin or triplet pregnancy $(n=4 ; O R=8.03 ; 95 \% \quad C l=0.84-190.23)$, and when mothers had preeclampsia $(n=16$; $\mathrm{OR}=11.56 ; 95 \% \mathrm{Cl}=3.11-50.77)$. Associations with pregnancy achieved with fertility treatment, and mother used iron supplements were also found. In conclusion, routine karyotype screening permits the diagnosis of chromosomal anomalies especially in those with the most severe forms of hypospadias and additional anomalies. Several risk factors have been identified for hypospadias which support the idea that genetic predisposition, placental insufficiency, and substances that interfere with natural hormones before conception or during fetal development play a role in the etiology of hypospadias.
\end{abstract}

\section{INTRODUCTION}

Hypospadias is one of the most opening anywhere along the shaft of the common developmental disorder of the penis, scrotum, or perineum. Hypospadias urogenital tract, with an estimated is often associated with a deficient prepuce prevalence of 3 to 8 per 1000 male and chordee. The malformation results livebirths ${ }^{[1,2]}$. Defined as an atypical urethral from incomplete fusion of the urethral folds

\footnotetext{
*Human Genetics Department, Medical Research Institute, University of Alexandria
} 
which usually occurs between 7th and 14th weeks of gestation ${ }^{[3]}$. Hypospadias usually occurs as an isolated defect, but can be part of a recognized syndrome or associated with other genital anomalies ${ }^{[4]}$. Known etiological factors are the same as those of intersex disorders and include complex genetic syndromes, and chromosomal abnormalities Among single etiological factors chromosomal abnormalities are found in $5 \%$ to $12 \%$ of cases $^{[5,6]}$.

The etiology of nonsyndromic hypospadias is unknown, and is believed to be multifactorial. An etiological role for genetic and environmental factors has been postulated since ethnic as well as geographic differences in incidence exist and the incidence is increasing in many countries [6]. Recent studies have implicated factors such as familial inheritance, low birth weight, advanced maternal age, paternal subfertility, and environmental exposure in the form of endocrine disruption chemicals in the pathogenesis of hypospadias ${ }^{[4,7]}$. Endocrine disruptors are exogenous substances that behave similarly to biologic hormones and is the most likely explanation for the worldwide increase in incidence in the last three decades. They interfere with the physiologic functions of the endogenous hormones by affecting the release, binding, or metabolism of the endogenous hormones,..., etc. An example of such is the non-steroidal estrogen diethylstilbestrol (DES) ${ }^{[7]}$.

The aim of the present study was to identify a wide range of risk factors for hypospadias in which we focused on both paternal and maternal factors and chromosomal disorders. This may assist in prevention of this congenital malformation, provide genetic counseling for affected families with hypospadias, and minimize or eliminate exposure to environmental agents that may contribute to this problem. 


\section{MATERIAL AND METHODS}

The study included 176 cases with different degrees of hypospadias referred to the Genetic Clinic, Medical Research Institute, University of Alexandria. Most of the patients presented with intermediate defect (penile hypospadias) (106/176; $60.23 \%$ ). Mild (glandular or/coronal and severe (scrotal or/perineal) manifestations of hypospadias were seen in $8.25 \%$ $(15 / 176)$ and $31.25 \%(55 / 176)$ of the patients, respectively. All cases were subjected to detailed family, pregnancy and genetic histories, clinical examination and pedigree study. Chromosomes analysis was performed in peripheral blood lymphocyte cultures according to standard protocols using G-banding technique ${ }^{[7]}$. Hormonal assays and, abdominal and pelvic ultrasound were carried out according to case presentation.

\section{Data collection:}

Both parents of cases and control group were asked to fill out the same written questionnares. The questionnares for both sets of parents contained questions on age, ethinity, and medical history. Information was requested on the 3 months immediately prior to conception and the first trimester of pregnancy with respect to illnesses, and medication. Additionally, mothers were asked about oral contraceptive use, assisted reproductive techniques, the course of pregnancy, their son"s birth weight, and the diagnosis of hypospadias or other congenital defects. Finally, the mothers were asked to provide information on their other children and pregnancies.

Statistical analysis:

Subjects with chromosomal abnormalities were excluded from the association study. A group of age and sexmatched children (300 boys) with normal development were included as a control group for the association study. Univariate analysis was used to test hypospadias risk factors. All potential risk factors, with the 
exception of birth weight, maternal age, autosomal aberrations $(30.43 \%)$ were and paternal age, were dichomotos (yes observed in these cases. We identified vs. no). Crude associations with Klinfelter syndrome in 3 cases, other hypospadias were estimated by odds ratios aberrations of the sex chromosomes in 13 (OR) with 95\% confidence intervals cases and autosomal chromosome $(95 \% \mathrm{Cl})$ in univariable analyses. Odds ratios greater than one indicate increased risks for hypospadias, especially when the lower bound of the $95 \% \mathrm{Cl}$ excludes unity. Subsequently, all potential risk factors were simultaneously included in logistic regression models in order to assess their independent contribution to the risk of hypospadias.

\section{RESULTS}

The age of the studied cases ranged from 6 days to 15 years. Chromosome abnormalities were identified in 23 of the 176 patients with hypospadias (13.07\%), they were detected only in cases with other associated anomalies. Most of the abnormalities were found in severe type of hypospadias (7.95\%) (Table 1). Sex chromosome abnormalities (69.56\%) and abnormalities in 7 cases (Table 2).

The 23 patients with chromosome abnormalities were excluded from the association study and statistical analysis for risk factors were done on 153 cases with isolated hypospadias, compared to 300 boys as a control group. The crude odds ratios and $95 \%$ confidence interval for the analysis of cases with hypospadias and the control are presented in table 3. Our data did not support an association with increased maternal age (>35ys). The most profound result was the increased risk of hypospadias for boys with positive family history ( $n=23 ; \quad O R=26.36$; 95\%Cl: 5.90164.23). Strong indications for an increased risk of hypospadias were also found with low birth weight $(n=45$; $\mathrm{OR}=13.47 ; \quad 95 \% \mathrm{Cl}=6.09-30.70)$, preterm 
birth $\quad(n=6 ; \quad O R=12.20 ; \quad 95 \% C l=1.45-\quad$ hypospadias as obtained from the 271.47), twin or triplet pregnancy $(n=4$; multivariable analysis using a conditional $\mathrm{OR}=8.03 ; 95 \% \mathrm{Cl}=0.84-190.23)$, and when logistic regression model. The full model mothers had preeclampsia $(n=16$; contained all risk factors that showed an $\mathrm{OR}=11.56$; $\quad 95 \% \mathrm{Cl}=3.11-50.77)$. indication for an association with Associations with increased patterned age hypospadias in the previous analysis (table pregnancy achieved with fertility treatment, 3). Overall, the effect estimate and mother used iron supplements were corresponded with the univariable analysis also found.

with the exception of increased paternal

Table 4 shows the independent effect age which did not appear to contribute to estimates for the risk factors that were the risk of hypospadias. found to contribute to an increased risk of 
Table 1: Chromosome constitution and the type of hypospadias

\begin{tabular}{|l|c|c|c|}
\hline \multicolumn{1}{|c|}{ Type of hypospadias } & $\begin{array}{c}\text { Normal } \\
\text { chromosome } \\
\text { No (\%) }\end{array}$ & $\begin{array}{c}\text { Chromosome } \\
\text { abnormality } \\
\text { No (\%) }\end{array}$ & \multicolumn{2}{|c|}{ Total } \\
No (\%)
\end{tabular}

Table 2: Chromosome abnormalities in cases with hypospadias

\begin{tabular}{|c|c|c|c|}
\hline Karyotype & NO. & $\%$ & ASSOCIATED ANOMALIES \\
\hline $\begin{array}{l}\text { Abnormal sex chromosome } \\
\text { karyotypes }\end{array}$ & & 69.56 & \\
\hline $47, X X Y$ & 3 & & $\begin{array}{ll}\begin{array}{l}\text { Cryptorchidism, } \\
\text { hypoplasia, small penis }\end{array} & \text { testicular }\end{array}$ \\
\hline $45, \mathrm{X} / 46, \mathrm{XY}$ & 4 & & $\begin{array}{l}\text { Cryptorchidism with or without } \\
\text { small penis }\end{array}$ \\
\hline $45, \mathrm{X} / 46, \mathrm{X}, \operatorname{idic}(\mathrm{Y})$ & 2 & & Cryptorchidism, small penis \\
\hline $46, X Y / 46, X X$ & 2 & & Cryptorchidism \\
\hline 46,XX (true hermaphrodite) & 3 & & Cryptorchidism \\
\hline $46, \mathrm{X}, \operatorname{idic}(\mathrm{Y})$ & 2 & & Cryptorchidism \\
\hline Abnormal autosome karyotypes & & 30.43 & \\
\hline $45, X Y, t(13 ; 14)$ & 1 & & Short stature, dysmorphic features \\
\hline $46, X Y, \operatorname{inv}(9)(p 11 q 13)$ & 1 & & $\begin{array}{l}\text { Dysmorphic features, delayed mile } \\
\text { stones }\end{array}$ \\
\hline $47, X Y,+21$ & 4 & & $\begin{array}{l}\text { Dysmorphic features, Unilateral } \\
\text { cryptorchidism }\end{array}$ \\
\hline $47, X Y,+18$ & 1 & & $\begin{array}{l}\text { Dysmorphic features, bilateral } \\
\text { cryptorchidism, congenital heart } \\
\text { disease }\end{array}$ \\
\hline Total & 23 & 100 & \\
\hline
\end{tabular}


Table 3: Association between hypospadias and potential risk factors using univariate analysis

\begin{tabular}{|l|c|c|c|c|c|}
\hline \multicolumn{1}{|c|}{ Risk Factors } & \multicolumn{2}{|c|}{$\begin{array}{c}\text { Number of cases } \\
(\mathrm{n}=153)\end{array}$} & \multicolumn{2}{c|}{$\begin{array}{c}\text { Number of controls } \\
(\mathrm{n}=300)\end{array}$} & $\begin{array}{c}\text { Crude Odds Ratio } \\
(95 \% \mathrm{Cl})\end{array}$ \\
\hline & No & $\%$ & No & $\%$ & \\
\hline $\begin{array}{l}\text { Increased maternal age } \\
(>35 y)\end{array}$ & 9 & 5.88 & 19 & 6.33 & $0.92(0.38-2.22)$ \\
\hline $\begin{array}{l}\text { Increased paternal age } \\
(>45 y)\end{array}$ & 20 & 13.07 & 12 & 4 & $3.61(1.62-8.11)$ \\
\hline $\begin{array}{l}\text { Family history of } \\
\text { hypospadias }\end{array}$ & 23 & 15.03 & 2 & 0.67 & $26.36(5.90-164.23)$ \\
\hline $\begin{array}{l}\text { Pregnancy achieved } \\
\text { with fertility treatment }\end{array}$ & 14 & 0.90 & 10 & 3.33 & $2.92(1.18-7.29)$ \\
\hline $\begin{array}{l}\text { Mother used iron } \\
\text { supplements }\end{array}$ & 22 & 14.38 & 14 & 4.67 & $3.43(1.62-7.33)$ \\
\hline Maternal preeclampsia & 16 & 10.46 & 3 & 1 & $11.56(3.11-50.77)$ \\
\hline $\begin{array}{l}\text { Twin or triplet } \\
\text { pregnancy }\end{array}$ & 4 & 2.61 & 1 & 0.33 & $8.03(0.84-190.23)$ \\
\hline Preterm birth birth & 45 & 29.41 & 9 & 3 & $13.47(6.09-30.70)$ \\
\hline $\begin{array}{l}\text { Low } \\
\text { weight(<2500gm) }\end{array}$ & 6 & 3.92 & 1 & 0.33 & $12.20(1.45-271.47)$ \\
\hline
\end{tabular}

Cl: Confidence interval

Table 4: Multivariate analysis of risk factors for hypospadias using logistic regression models

\begin{tabular}{|l|l|l|}
\hline Risk Factors & Odds Ratio & $95 \% \mathrm{Cl}$ \\
\hline Increased paternal age (>45y) & 2.693 & $0.967-7.497$ \\
\hline Family history of hypospadias & $26.272^{\star}$ & $5.249-131.491$ \\
\hline $\begin{array}{l}\text { Pregnancy achieved with } \\
\text { fertility treatment }\end{array}$ & $3.123^{\star}$ & $1.031-9.463$ \\
\hline Mother used iron supplements & $5.708^{*}$ & $2.381-13.680$ \\
\hline $\begin{array}{l}\text { Maternal preeclampsia or } \\
\text { hypertension }\end{array}$ & $57.193^{\star}$ & $6.932-471.896$ \\
\hline Twin or triplet pregnancy & $17.237^{\star}$ & $1.522-195.216$ \\
\hline Preterm birth & $11.154^{\star}$ & $1.804-68.986$ \\
\hline Low birth weight(<2500gm) & $19.191^{\star}$ & $8.249-44.647$ \\
\hline
\end{tabular}

* Statistically significant $\mathrm{Cl}$ : Confidence interval 


\section{DISCUSSION}

Hpospadias is one of the most common congenital anomalies in the male baby. Studies on the etiology of hypospadias are available and most of them favour a multifactorial inheritance Multiple genetic factors combine with environmental factors during early pregnancy when hypospadias occur ${ }^{[9,10]}$.

The severity of hypospadias in our study was $8.52 \%$ glandular or coronal; $60.23 \%$ penile; and $31.25 \%$ perineal or scrotal defects. This is different from that recorded in other studies where $68.7 \%$ were distal; $24.8 \%$ penile, and $6.3 \%$ perineal[9-11]. The discrepancy is most propably due to the selection criteria of the sample used as mild defects are not usually referred for genetic evaluation.

Chromosome abnormalities were identified in 23 of the 176 patients with hypospadias (13.07\%) in the present study, they were detected in cases with other associated anomalies. Several reports of the incidence of chromosomal anomalies in patients with hypospadias have been published. Moreno-Garcia and Miranda[12] identified chromosomal anomalies in $7 \%$ of males with hypospadias, while Yamaguchi et al., ${ }^{[5]}$ detected them in $11.11 \%$. McAleer and Kaplan[13] concluded that those with the most severe forms of hypospadias, particularly at the perineal meatus location, have a higher likelihood of intersex or sex chromosome abnormality, a finding which is present in our study. Most reports involve small series of patients with a small number of abnormal karyotypes, and so they may not reflect the true incidence of chromosomal abnormalities. When cryptorchidism is associated with hypospadias, the incidence of chromosomal anomalies is higher than in patients with only cryptorchidism or hypospadias $^{[13]}$.

Although hypospadias is common, risk factors for this birth defect are relatively poorly defined. Familial aggregation is well 
recognized[14], but other risk factors are more controversial[15].

In the present study we did not found a positive association between advanced maternal age and hypospadias. Muliple studies investigating hypospadias did not report an association with maternal age ${ }^{[16,17]}$. However, Fisch et al..,[18] reported a $50 \%$ higher risk of hypospadias among women $>35$ years of age, compared with women $<20$ years of age. Other studies reported similar results and demonstrated a linear relationship between maternal age and hypospadias risk, with risk nearby doubling by time women were $>40$ years of age ${ }^{[1,19]}$. It is not known why maternal age may be a risk factor for hypospadias. They concluded that older women are at higher risk of having children with genetic defects. It is therefore plausible that the risk is mediated via underlying genetic defects associated with aging. Some authers have suggested that subfertility is a potential mechanism linking hypospadias with maternal age, because subfertile women often are older at the time of first conception $^{[3]}$. Increased paternal age did not appear to contribute to increased risk of hypospadias in the present study. This is in agreement with previous studies which did not report any association between paternal age and hypospadias ${ }^{[17,19]}$.

The most profound association revealed in this study was the increased risk of hypospadias among boys with family history of hypospadias (15.03\%). This seems to be compatible with previous studies which reported that hypospadias affects about $7 \%$ of first-, second-, and third-degree relatives of cases. Pedigree data do not suggest a Mendelian pattern of inheritance, and a multifactorial pattern is the most consistent explanation for familial clustering of severe hypospadias. The familial clustering of hypospadias among first-degree relatives has traditionally been perceived as evidence of a genetic component in the etiology of this anomaly 
[20]. However, exposure to environmental contaminants is now being considered in familial clusters because of the high probability of shared exposures among first-degree relatives [21]. The overall risk for a brother of an affected infant to also have hypospadias was $9.6 \% .^{[3,22]}$ These sibs occurrence risks are compatible with a multifactorial mode of inheritance for hypospadias.

Consistent with previous literature ${ }^{[10,11,23]}$, we found an increased occurrence of hypospadias in children with low birth weight, preterm pregnancy, or born out of a multiple pregnancy. In these pregnancies, the placenta may have been insufficient in providing the fetus with nutrients and gonadotropins, of which Human Chorionic Gonadotropin (HCG) appears to play a specific role in male sexual differentiation. This may have led to both growth restriction, to which twins and triplets are more susceptible, and hypospadias ${ }^{[24]}$. An increased risk for hypospadias among twins has been described by Kallen et al.[22] Concordance among twins of the same sex was $18 \%$ for both mild and severe forms, with increased risk evident in both monozygotic and dizygotic twins. When monozygotic twins discordant for hypospadias were evaluated, the twin with the lowest birth weight had hypospadias suggesting a gene-environment interaction[25].

Our results also point towards an association between fertility treatment and hypospadias. An increased risk of secondand third degree hypospadias was found among infants delivered to women who took progestins during early pregnancy to help them become pregnant or to prevent pregnancy complications or loss, the odds ratios suggested a least 2 -fold increased risk $^{[26,27]}$. In previous studies, an increased occurrence of hypospadias was reported following IVF and ICSI treatments[28,29]. One possible explanation is that hormones administered as part of fertility treatment 
interfere with male sexual hormones in early gestation and thereby disturb normal genital development. Progesterone used to support pregnancies achieved with ART, in particular, may impair testosterone production or its conversion to $\mathrm{DHT}^{[26]}$.

An increased risk of hypospadias was found in the present study when mothers used iron supplements immediately prior to conception and/or during the first trimester of pregnancy. This association was previously reported in several studies ${ }^{[10,30]}$. Iron deficiency anemia in early pregnancy has been associated with preterm delivery, possibly due to long-term hypoxia and oxidative stress ${ }^{[31]}$. Furthermore, it has been suggested that iron supplementation in mothers who are not iron deficient may cause toxic reactions or increase blood viscosity, which subsequently impairs placental blood flow ${ }^{[32]}$.

Like Akre et al., ${ }^{[33]}$ and Chong et al.,[23] maternal preeclampsia was found to be significantly associated with hypospadias in our study. Whether and how maternal preeclampsia, a late gestational event, relates to the development of the external genitalia remains unclear ${ }^{[34]}$. Akre et al., ${ }^{[35]}$ concluded that this association was compatible with a role for placental insufficiency in the etiology of hypospadias. In conclusion, routine karyotype screening permits the diagnosis of chromosomal anomalies especially in those with the most severe forms of hypospadias and associated anomalies. Several risk factors have been identified for isolated hypospadias including, preterm births, twin pregnancy, maternal preeclampsia, and pregnancy achieved with fertility treatment. Familial clustering has been well documented, and may involve both genetic and environmental risk factors. The use of iron supplements by mothers also appeared to be associated with hypospadias. These risk factors support the idea that genetic predisposition, placental insufficiency, and 
substances that interfere with natural

hormones before conception or during fetal

development play a role in the etiology of

hypospadias. Larger studies could facilitate

the identification of other risk factors as

well and provide opportunities for the

further in-depth investigation of the

association found to date. Identifying

various etiologies of hypospadias will allow

proper prenatal counseling for families with

history of hypospadias, and to minimize or

eliminate exposure to environmental

agents that may contribute to this problem.

\section{REFERENCES}

1. Carmichael SL, Shaw GM, Nelson V, Selvin S, Torfs CP, Curry CJ. Hypospadias in California: trends and descriptive Epidemiology. 2003;14:701-6.

2. Centers for Disease Control and Prevention. Evaluation of an association between loratadine and hypospadias: United States, 19972001. MMWR Morb Mortal WklyRep. 2004;53:219-21.

3. Manson JM, Carr MC. Molecular epidemiology of hypospadias: Review of genetic and environmental risk factors. Birth Defects Res Part A-Clin Mol Teratol. 2003;67:825-36.

4. Stokowski LA. Hypospadias in neonate. Adv Neonatal Care. 2004;4(4):206-15.
5. Yamaguchi T, Kitada S, Osada Y. Chromosomal anomalies in cryptorchidism and hypospadias. Urol Int. 1991;47:60-5.

6. Boehmer LA, Nijman JR, Lammers AB, De Conink JS, Van Hemel OJ, Themmen PA, et al. Etiological studies of severe or familial hypospadias. J Urol. 2001;165:1246-54.

7. Wang $\mathrm{MH}$, Baskin L. Endocrine disruptors, genital development and hypospadias. J Androl. 2008;22:1-20.

8. Seabright M. A rapid banding technique for human chromosomes. Lancet. 1971; ii:971.

9. Stoll C, Alembik Y, Roth MP. Dott B. Genetic and environmental factors in hypospadias. J Med Genet. 1990;27:559-63.

10. Brouwers MM, Feitz FW, Roelofs AL, Kiemeney AL, de Gier-Nel Roeleveld PR. Risk factors for hypospadias. Eur J Pediatr. 2007;166:671-8.

11. Fredell L, Ingrid K, Hansson $E$, Holmner S, Lundquist L, Lackgren G, et al. Heredity of hypospadias and the significance of low birth weight. J Urol. 2002;167:1423-7.

12. Moreno-Garcia M, Miranda EB. Chromosomal anomalies in cryptorchidism and hypospadias. J Urol. 2002;168:2170-2.

13. McAleer IM, Kaplan GW. Is routine karyotyping necessary in the evaluation of hypospadias and cryptorchidism? J Urol. 2001;165:202932.

14. Harris EL. Genetic epidemiology of hypospadias. Epidemiol Rev. 1990;12:29-40.

15. Hussain N, Chaghatai A, Herndon CD, Herson VC, Rosenkrantz TS, McKenna $\mathrm{PH}$. Hypospadias and early gestation growth restriction in infants. Pediatrics. 2002;109:473-8.

16. Weidner IS, Moller $H$, Jensen TK, Skakkebaek NE. Risk factors for 
cryptorchidism and hypospadias. J Urol. 1999;161:1606-9.

17. Pierik FH, Burdorf A, Deddens JA, Juttmann RE, Weber RF. Maternal and paternal risk factors for cryptorchidism and hypospadias: A case control study in newborn boys. Environ Health Perspect. 2004;112(15):1570-6.

18. Fisch H, Golden RJ, Libersen GL, Hyun GS, Madsen P, New MI, et al. Maternal age as a risk factor for hypospadias. J Urol. 2001;165:934-6.

19. Porter MP, Faizan MK, Grady RW, Mueller BA. Hypospadias in Washington State: Maternal risk factors and prevalence trends. Pediatr. 2005;115:e495-9.

20. Fredell $L$, Iselius $L$, Collins $A$, Hansson E, Holmner S, Lundquist L, G, et al. Complex segregation analysis of hypospadias. Hum Genet. 2002;111:231-4.

21. Baskin LS, Himes K, Colborn T. Hypospadias and endocrine disruption: is there a connection? Environ Health Perspect. 2001;109:1175-83.

22. Kallen B, Bertolini R, Castilla A. A joint international study on the epidemiology of hypospadias. Acta Peadiatr Scand Suppl. 1986;324:1-52.

23. Chong JH, Wee CK, Ying Ho SK, Lin Chan DK. Factors associated with hypospadias in Asin newborn babies. J Perinat Med. 2006;34:497-500.

24. Fujimoto T, Suwa T, Kabe K, Adachi T, Nakabayashi M, Amamiya T. Placental insufficiency in early gestation is associated with hypospadias. J Pediatr Surgery, 2008;43:358-61.

25. Fredell L, Lichtenstein P, Pedersen NL, Svensson J, Nordenskjold A. Hypospadias is related to birth weight in discordant monozygotic twins. J Urol. 1998;160:2197-9.

26. Carmichael SL, Shaw GM, Laurent C, Croughan MS, Olney RS, Lammer EJ. Maternal progestin intake and risk of hypospadias. Arch Pediatr Adolesc Med. 2005;159:957-62.

27. Carmichael SL, Shaw GM, Laurent C, Olney RS, Lammer EJ. Maternal reproductive and demographic characteristics as risk factors for hypospadias. Paediatr Perinat Epidemiol. 2007;21(3):210-8.

28. Silver RL, Rodriguez R, Chang TS, Gearhart JP. In vitro fertilization is associated with an increased risk of hypospadias. J Urol.1999;161:1954-7.

29. Wennerholm UB, Bergh C, Hamberger $\mathrm{L}$, Lundin $\mathrm{K}$, Nilsson L, Wikland $\mathrm{M}$, et al. Incidence of congenital malformations in children born after ICSI. Hum Reprod. 2000;15:944-8.

30. North K, Golding J. A maternal vegetarian diet in pregnancy is associated with hypospadias. The ALSPAC Study Team. Avon Longitudinal Study of Pregnancy and Childhood. Brit J Urol Int. 2000;85:10713.

31. Allen LH. Multiple micronutrients in pregnancy and lactation: an overview. Am J Clin Nutr. 2005;81:1206S-12S.

32. Scholl TO. Iron status during pregnancy: setting the stage for mother and infant. Am J Clin Nutr. 2005;81:1218S-22S.

33. Akre O, Lipworth L, Cnattingius $S$, Sparen P, Ekbom A. Risk factor patterns for cryptorchidism and hypospadias. Epidemiol. 1999;10:36471.

34. Pedersen L, Skriver MV, Norgaad M, Sorensen HT. Maternal use of Loratidine during pregnancy and risk of hypospadias in offspring. Int $\mathrm{J}$ Med Sci. 2006;3:21-5.

35. Akre O, Boyd HA, Ahlgren M, Wilbrand $\mathrm{K}$, Westergaard $\mathrm{T}$, Hjalgrin $\mathrm{H}$, et al. Maternal and gestational risk factors for hypospadias. Environ Health Perspect. 2008;116(8):1071-6. 